\title{
Disproportionality and Risk of High School Students Suspensions due to Non-parental Involvement
}

\author{
Khairul Islam ${ }^{1 *}$ and Tanweer J Shapla ${ }^{2}$ \\ ${ }^{1,2}$ Department of Mathematics and Statistics \\ Eastern Michigan University, Ypsilanti, MI 48197, USA \\ *E-mail of the corresponding author: kislam@emich.edu
}

\begin{abstract}
A recent study (Bryant \& Wilson, 2020) investigates disproportionality of Charter High School students' suspensions due to students' ethnicity, socioeconomic status and gender, and it concludes that ethnicity and social status significantly affect students' suspension. Many researches argue that parental activity is significantly related to improved students' outcome (e.g., see Liu et al., 2020). However, the parental and family involvement activities have not been investigated in relation to the high school students' suspension. The purpose of this study is to investigate high school students' suspension due to ethnicity, socioeconomic status and gender adjusted for the parental and family involvement factors in education and vice versa, by employing the data from the United States National Household Education Surveys. Bivariate analyses suggest that six out of the eight parental factors are significantly related to high school students' suspension (chi-squared pvalue $<0.05$ ). Adjusted multiple logistic regression analyses suggest that four out of the eight parental involvement factors significantly ( $\mathrm{p}$-value $<0.05$ ) affect high school students' suspension with non-parental involvement showing higher odds of suspension. Our findings have significant implications for practicing and policymaking, as educators and policymakers seek to reduce students' suspension in the face of adverse students' outcomes.
\end{abstract}

Keywords: Highschool students' suspension, Parental involvement, Adjusted analysis, Multiple logistic regression.

DOI: $10.7176 / \mathrm{MTM} / 11-4-03$

Publication date:September $30^{\text {th }} 2021$

\section{Introduction}

Students' suspensions are disciplinary actions in response to students' behavior, which include in-school or outof-school suspensions and expulsions from schools (National Center for Education Statistics, 2019). Students receive temporary removal from the regular classes to be kept with the direct supervision of school personnel for at least half a day. In an out-of-school suspension, students receive temporary removal from the regular school to be sent in alternative settings. For an expulsion, students receive removal from the regular school for the remainder of the school year or longer in accordance with local education agency policy.

Evidence of disproportionate students' suspension exists in the United States (Arcia, E., 2007; Bland \& Mitchell, 2018; Gopalan \& Nelson, 2019; Hoffmann, 2017; Lewis et al., 2010; Loveless, 2017; Morris \& Perry, 2017; Skiba et al., 2012; Smith \& Harper, 2015; Sparks, 2018; Stetson \& Collins, 2010), with students of color receiving two to three times higher suspension rates compared to students with other ethnic groups at the elementary, middle, and high school levels (Bland \& Mitchell, 2018; Morris \& Perry, 2017; Skiba et al., 2012; Sparks, 2018). Research also suggests that the disproportionate suspension of students of color is a national problem and a disturbing issue for schools in the United States (Bland \& Mitchell, 2018; Lewis et al., 2010; Loveless, 2017; Morris \& Perry, 2017; Skiba et al., 2012; Sparks, 2018; Stetson \& Collins, 2010).

The adverse consequences of students' suspensions are quite enormous. Suspension is related to the lower rates of academic achievement for students of color (Gregory et al., 2010) and it may increase disciplinary referrals (Atkins et al., 2002). Repeatedly disciplined students are more likely to drop out from schools (Fabelo et al., 2011). Suspended students are often viewed as problem students, a perception that is difficult to change (Kennedy-Lewis et al., 2016; Weissman, 2015). Suspension may lead to subsequent participation in juvenile and criminal justice systems (Fabelo et al., 2011; Noguera, 2003; Toldson, 2011), and it may have tremendous economic costs to the lives of suspended students, the school and society (Marchbanks et al., 2015). Suspensions funnel students of color out of classrooms and into jail cells (Weissman, 2015). 
Given the evidence of disproportionate students' suspensions and the noted adverse consequences of suspensions, it has become inevitable to look for factors that might contribute in the reduction of high school students' suspension. Since the previous studies did not address the factors that may contribute to why students are being suspended (Bryant \& Wilson, 2020), they have addressed the contribution of a few factors such as socioeconomic status, gender, and ethnicity in reference to suspension in a local affiliated charter high school in southern California. We postulate that parental involvement in education would assist in reducing students' suspension. Understanding significant parental involvement types may contribute towards intervention or incentives for higher parental involvement in education. In this note, we would like to refer to a good number of researches which focus on ways parents can get involved in school activities or education (Reinke et al., 2019; Smith \& Sheridan, 2019) or how parental involvements impact in students' achievement or performance (Boonk et al., 2018; Dotterer \& Wehrspann, 2016; Grace \& Gerdes, 2019; Smith \& Sheridan, 2019; Tan et al., 2019; Thompson et al., 2017), including Liu et al. (2020), which provides a further more literatures addressing the of benefits of parental involvement in education. However, none of these studies address the contribution of parental involvement in relation to high school students' suspension and of its reduction.

This study investigates if parental involvement factors directly or adjusted for students' ethnicity, socioeconomic status, and gender predict the likelihood of high school (HS) students' suspensions using a broad database due to the National Household Education Surveys 2019. Findings of this study are expected to instrumental to educators and policymakers as they seek to reduce students' suspension in the face of adverse students' outcomes.

\section{Methods}

In this section, we outline aim of this study, research questions and hypotheses, sample, and statistical analyses techniques.

\subsection{Aim of the study}

The aim of this study is to determine if parent and family involvement (PFI) factors predict the odds of high school students' suspension in the United States, adjusted for ethnicity, socioeconomic status, and gender, and vice versa. The specific aims of this study are

(i) to investigate if ethnicity, socioeconomic status, and gender predict the odds of high school students' suspension;

(ii) to investigate if the set of eight PFI factors such as attending a school event (ase), serving as a volunteer (vol), attending school meeting (asm), attending parent - teacher organization meeting (aptm), attending parent - teacher conference (aptc), participating in fundraising (fund), serving on school committee (sosc), meeting with guidance counselor (mwgc) predict the odds of high school students' suspension;

(iii) to investigate if any of the set of factors in (i)-(ii) adjusted for the other set predict the odds of the high school students' suspension.

This study extends the existing literature such as Bryant \& Wilson (2020) by incorporating PFI factors in predicting the likelihood or odds of high school student' suspension in the United States.

\subsection{Research questions and hypotheses}

We formulate the following research questions and hypotheses to fulfil our aims:

Research Question 1: Are eight PFI factors as well as ethnicity, socioeconomic status and gender associated with high schools' student suspension?

Null Hypothesis 1: PFI factors as well as ethnicity, socioeconomic status and gender are not associated with HS student's suspensions. 
Alternative Hypothesis 1: PFI factors as well as ethnicity, socioeconomic status and gender are associated with HS student's suspensions.

Research Question 2: What are the predictive relationships between PFI factors as well as ethnicity, gender, and socioeconomic status for the odds of HS students' suspensions?

Null Hypothesis 2: PFI factors as well as ethnicity, gender, and socioeconomic status do not predict the odds of HS students' suspensions.

Alternative Hypothesis 2: PFI factors as well as ethnicity, gender, and socioeconomic status do predict the odds of HS students' suspensions.

\subsection{Sample}

This study utilizes a sample of 6,086 high school students with a complete suspension status available from the Parent and Family Involvement (PFI) in Education Survey 2019, which represents a population of 51.5 million K-12 students covering the 50 States and the District of Columbia of the United States. It is to be noted that the PFI has been administered as part of the National Household Education Surveys (NHES) Program (2019). The sample of 6,086 high school students has been derived from the actual sample of 16,446 K-12 students representing the specified population in the PFI Surveys 2019.

The response variable, suspension status (Yes/No), is defined by in-school suspensions or out-of-school suspensions or expulsions from schools. Predictors are eight PFI factors (each with values Yes/No) as well gender, ethnicity (having values $1=$ Non-Hispanic White, 2=NH Black, 3=Hispanic, 4=NH Asian/PI, and $5=$ Others) and socioeconomic factor defined by the poverty status (poor, non-poor) due to the algorithm in Hanson et al. (2020).

The NHES or the PFI surveys are equipped with a survey weight variable named FPWT (called the final parent interview weight), which has been utilized in all analyses under taken in this study. For presentational convenience we use the notation $w_{i}$ to refer to the weight assigned to sampling unit $j$ in the study.

\subsection{Analysis Methods}

In order to answer research question 1 and test of related hypotheses, we perform bivariate analyses by implementing chi-squared test. For any sampling unit $j$, let $W_{i}$ denote the sampling weight available from the NHES or PFI surveys 2019. For each predictor factor with levels $t-1_{,} z_{, \ldots}, I$ and suspension status $k, k-1$ if suspended (or 2 if non-suspended), let $\widehat{N}_{i k}=\Sigma_{j} W_{j}(i, k)$ such that $W_{i}(i, k)=W_{i}$ if the sampling unit $j$ belongs to the cell $\left(i_{x} k\right)$. Then, $\widehat{\mathbb{N}}_{i k}$ refers to the estimated weighted of total in the $\left(i_{x} k\right)$ cell. Similarly, let $\hat{\mathbb{N}}_{i}$ and $\hat{\mathbb{N}}_{k}$ refer to estimated weighted total in row $i$ and column $k$. Under these notational simplicities, we can form the following bi-variate summary table for each predictor factor and suspension status of the students

\begin{tabular}{|c|c|c|c|}
\hline & Response (Suspension status) & & \\
\hline Factor levels & Yes $=1$ & No $=2$ & Total \\
\hline 1 & $\tilde{N}_{11}$ & $\tilde{N}_{12}$ & $\tilde{N}_{1}$ \\
\hline 2 & $\tilde{N}_{21}$ & $\tilde{N}_{2 z}$ & $\tilde{N}_{2}$ \\
\hline$\vdots$ & $\vdots$ & $\vdots$ & $\vdots$ \\
\hline I & $\hat{N}_{s 1}$ & $\tilde{N}_{n}$ & $\tilde{N}_{t}$ \\
\hline Total & $\mathbb{N}_{-1}$ & $\mathbb{N}_{2}$ & $\mathbb{N}$ \\
\hline
\end{tabular}


Then, the chi-squared test of association between a given factor and high school student's suspension is given by the following test statistic

$\chi^{2}=\sum_{i=1}^{I} \sum_{k=1}^{2} \frac{\left(\tilde{N}_{i k}-E_{i k}\right)^{2}}{E_{i k}}$

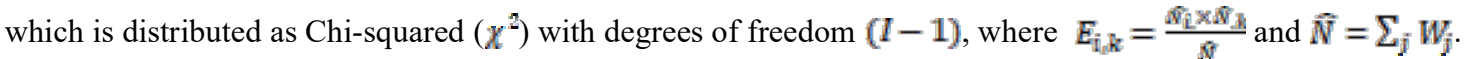
We utilize SAS Proc SurveyFreq procedure for implementing this test (SAS Institute, 2017).

To answer research question 2 and related hypotheses, we employ three models of multiple logistic regression analyses-(i) Model 1 (M1) incorporating factors such as gender, ethnicity and socioeconomic status (unadjusted due to PFI factors), (ii) Model 2 (M2) with PFI factors (unadjusted due to gender, ethnicity and socioeconomic factors) and (iii) finally model 3 (M3) with PFI factors and gender, ethnicity and socioeconomic status to investigate the adjusted effect of a given factor when other factors are considered fixed. The general form of an $L$-factor multiple logistic regression model with $l$ th factor having $I_{l}$ labels is specified by

$\log \left(\frac{\pi}{1-\pi}\right)=\alpha+\sum_{i=1}^{L} \sum_{i=1}^{I_{i}-1} \beta_{\mathrm{ii}} x_{\mathrm{ii}}$

where $\pi$ is the probability of receiving a suspension, $\alpha$ is the intercept and $\beta_{l i}$ is the effect of $i$ th level of $l$ th factor, $l=1_{x} 2_{x, n} L_{s} i=1_{x} 2_{s, n} I_{l}$. For each factor, one level of a factor will be considered as a base-label category, which enable us to evaluate risk of the event for a given factor level compared to the base level, when other factors remain fixed. In this paper, we analyze the risk of suspension defined by the odds-ratio estimates due to PFI factors and other underlying factors. We utilize SAS Proc SurveyLogistic procedure (SAS Institute, 2017) to implement models M1-M3

\section{Results}

This study shows that $15.4 \%$ students receive high school suspensions. The results of research question 1 and related hypotheses are derived from the bi-variate analyses of the predictors for possible association with high school students' suspension via chi-squared tests. The summary of the results is presented in Table 1 in terms of percent (\%) received suspension (Yes or No), along with the standard error (SE) of the \% estimates, and values of the Chi-squared test (chisq) together with the associated p-values (pvalue).

Table 1: Results of Chi-squared Tests of Association Between Various Factors and High School Students' Suspension Status

\begin{tabular}{|c|c|c|c|c|c|c|c|}
\hline \multirow[b]{3}{*}{ Variables } & & \multicolumn{4}{|c|}{ Received suspension } & \multirow[b]{3}{*}{ chisq } & \multirow[b]{3}{*}{ pvalue } \\
\hline & & \multicolumn{2}{|l|}{ Yes } & \multicolumn{2}{|c|}{ No } & & \\
\hline & Values & $\%$ & SE (\%) & $\%$ & SE (\%) & & \\
\hline \multirow{2}{*}{ Gender } & Male & 10.9 & 0.67 & 41.6 & 0.93 & & \\
\hline & Female & 4.6 & 0.49 & 43.0 & 0.94 & 45.8 & $<.0001$ \\
\hline \multirow{5}{*}{ Ethnicity (eth) } & $1=\mathrm{NH}-$ White & 6.6 & 0.44 & 42.2 & 0.90 & & \\
\hline & $2=\mathrm{NH}-\mathrm{Black}$ & 3.9 & 0.51 & 9.1 & 0.58 & & \\
\hline & $3=$ Hispanic & 3.4 & 0.38 & 23.0 & 0.89 & & \\
\hline & $4=\mathrm{Asian} / \mathrm{PI}$ & 0.6 & 0.34 & 5.8 & 0.41 & & \\
\hline & $5=$ Others & 0.9 & 0.15 & 4.4 & 0.37 & 36.3 & $<.0001$ \\
\hline \multirow{2}{*}{ Poverty (pov) } & $1=$ Poor & 2.7 & 0.31 & 9.1 & 0.60 & & \\
\hline & $2=$ Nonpoor & 12.7 & 0.75 & 75.5 & 0.91 & 14.8 & 0.0001 \\
\hline \multirow{2}{*}{$\begin{array}{l}\text { Attend school event } \\
\text { (ase) }\end{array}$} & $1=$ Yes & 9.1 & 0.61 & 60.6 & 0.96 & & \\
\hline & $2=\mathrm{No}$ & 6.4 & 0.57 & 24.0 & 0.83 & 20.7 & $<.0001$ \\
\hline \multirow[t]{2}{*}{ Serve as volunteer (vol) } & $1=$ Yes & 3.0 & 0.33 & 27.0 & 0.80 & & \\
\hline & $2=\mathrm{No}$ & 12.4 & 0.75 & 57.5 & 0.95 & 25.1 & $<.0001$ \\
\hline
\end{tabular}




\begin{tabular}{|c|c|c|c|c|c|c|c|}
\hline \multirow{2}{*}{$\begin{array}{l}\text { Attend school meeting } \\
(\text { asm) }\end{array}$} & $1=$ Yes & 10.9 & 0.66 & 66.3 & 0.94 & & \\
\hline & $2=\mathrm{No}$ & 4.5 & 0.50 & 18.3 & 0.74 & 7.9 & 0.0048 \\
\hline \multirow{2}{*}{$\begin{array}{l}\text { Atten parent teacher } \\
\text { org. meeting (aptm) }\end{array}$} & $1=$ Yes & 5.9 & 0.46 & 32.5 & 0.90 & & \\
\hline & $2=\mathrm{No}$ & 9.6 & 0.69 & 52.1 & 0.96 & 0.0 & 0.8906 \\
\hline \multirow{2}{*}{$\begin{array}{l}\text { Attend parent teacher } \\
\text { conference (aptc) }\end{array}$} & $1=$ Yes & 9.0 & 0.61 & 45.0 & 0.94 & & \\
\hline & $2=\mathrm{No}$ & 6.5 & 0.57 & 39.6 & 0.93 & 2.6 & 0.108 \\
\hline \multirow{2}{*}{$\begin{array}{l}\text { Participate in fundraising } \\
\text { (fund) }\end{array}$} & $1=$ Yes & 5.7 & 0.54 & 41.8 & 0.93 & & \\
\hline & $2=\mathrm{No}$ & 9.7 & 0.64 & 42.8 & 0.94 & 16.0 & $<.0001$ \\
\hline \multirow{2}{*}{$\begin{array}{l}\text { Serve on school } \\
\text { committee (sosc) }\end{array}$} & $1=$ Yes & 0.9 & 0.16 & 10.0 & 0.50 & & \\
\hline & $2=\mathrm{No}$ & 14.5 & 0.78 & 74.6 & 0.86 & 15.6 & $<.0001$ \\
\hline \multirow{2}{*}{$\begin{array}{l}\text { Meet with guidance } \\
\text { counselor (mwgc) }\end{array}$} & $1=$ Yes & 8.4 & 0.54 & 38.1 & 0.93 & & \\
\hline & $2=\mathrm{No}$ & 7.0 & 0.64 & 46.5 & 0.94 & 9.5 & 0.002 \\
\hline
\end{tabular}

As we see from the results of Table 1 , all the factors are significantly associated (pvalue $<0.05$ ) with high school students' suspensions, except for two PFI factors - attending parent teacher organization meeting (aptm) and attending parent teacher conference (aptc).

In order to investigate and quantify the effects of underlying factors in predicting the likelihoods or odds of high school students' suspension, let us turn our attention to the results of multiple logistic regression models in Tables 2-4. In Tables 2-4, the reported odds ratio estimates (ORest) are the exponentiated values of the estimates of the model parameters, which are popular ways of measuring risk of an event due to various factor levels compared to the reference factor level. The reported point estimates of OR (ORest) along with the corresponding $95 \%$ confidence interval (CI) measure risk or odds of high school students' suspension for a given factor level compared to the reference level when other factors remain fixed. The significance of a factor level can be assessed looking at the $\mathrm{p}$-value of the test of the model parameter or $95 \%$ CIs of the odds ratio. If confidence interval estimates of a given factor level include 1, the factor level is interpreted as statistically insignificant compared to the reference level when other factors remain fixed. Likewise, if the confidence interval estimates of a given factor level do not include 1, the factor level is interpreted as statistically significant compared to the reference level when other factors remain fixed. Given these facts, for example, in Table 2, as we see the estimated odds of suspension of male students are 2.53 times the odds of female students with 95\% CI: (1.93, 3.22), not including 1 .

Table 2: Effect of Ethnicity, Gender and Poverty from M1 of Multiple Logistic Regression Analysis (Unadjusted Due to PFI Factors)

\begin{tabular}{lccccc}
\hline Effects & Est & tValue & Pvalue & OR & $95 \%$ CI (OR) \\
\hline eth 2 vs 1 & 0.976 & 5.55 & $<.0001$ & 2.66 & $\mathbf{( 1 . 8 8 , \mathbf { 3 . 7 5 } )}$ \\
eth 3 vs 1 & -0.096 & -0.65 & 0.5170 & 0.91 & $(0.68,1.21)$ \\
eth 4 vs 1 & -0.348 & -0.59 & 0.5580 & 0.71 & $(0.22,2.26)$ \\
eth 5 vs 1 & 0.224 & 1.12 & 0.2607 & 1.25 & $(0.85,1.85)$ \\
gender 1 vs 2 & 0.927 & 6.68 & $<.0001$ & 2.53 & $\mathbf{( 1 . 9 3 , 3 . 3 2 )}$ \\
pov 1 vs 2 & 0.495 & 3.02 & $\mathbf{0 . 0 0 2 5}$ & 1.64 & $\mathbf{( 1 . 1 9 , 2 . 2 6 )}$ \\
\hline
\end{tabular}

It is evident from the results of Table 2 that ethnicity is a significant factor which predicts the higher odds of suspension in NH-Black students $(\mathrm{OR}=2.66,95 \% \mathrm{CI}$ : 1.88-3.75) compared to the NH-White students (reference group). However, the odds of high school students' suspension in Hispanic, Asian/PI and Others (other race) compared to NH-White students are not significant. There is a clear evidence in the higher odds of suspension for male high school students $(\mathrm{OR}=2.53,95 \% \mathrm{CI}$ : 1.93-3.32) compared to female students. Socioeconomic status measured by poverty shows that poor high school students have higher odds of suspension compared to non-poor students.

In Table 3, while investigating the PFI factors for possible odds of suspension disproportionality, it is evident that six out of eight PFI factors are related to the disproportionality of high school students' suspension. Indeed, 
students with parents non-engaged in PFI activities such as attending school events (ase), serving as volunteers (vol), attending school meeting (asm) and serving on a school committee (sosc) have higher odds of suspensions compared to students whose parents are engaged in such activities. However, PFI factors involving in fundraising (fund) and attending parent teacher organizing meeting (aptm) are not significant for the odds of high school students' suspensions. PFI factors meeting with guidance counselor (mwgc) and attending parent teacher conference (aptc) are found to be preventing factors in that students with parents non-engaged in such activities have lower odds of suspension compared to students with parent engaged in such activities.

Table 3: Effect of PFI Factors from M2 of Multiple Logistic Regression Analysis (Unadjusted for Ethnicity, Gender and Poverty)

\begin{tabular}{lccccc}
\hline Effects & Est & tValue & Pvalue & OR & $95 \%$ CI (OR) \\
\hline ase 2 vs 1 & 0.357 & 2.77 & $\mathbf{0 . 0 0 5 6}$ & 1.43 & $\mathbf{( 1 . 1 1 , \mathbf { 1 . 8 4 } )}$ \\
vol 2 vs 1 & 0.430 & 2.70 & $\mathbf{0 . 0 0 6 9}$ & 1.54 & $\mathbf{( 1 . 1 3 , \mathbf { 2 . 1 0 } )}$ \\
asm 2 vs 1 & 0.317 & 2.19 & $\mathbf{0 . 0 2 8 3}$ & 1.37 & $\mathbf{( 1 . 0 3 , \mathbf { 1 . 8 2 } )}$ \\
aptm 2 vs 1 & -0.118 & -0.89 & 0.3755 & 0.89 & $(0.69,1.15)$ \\
aptc 2 vs 1 & -0.334 & -2.57 & $\mathbf{0 . 0 1 0 3}$ & 0.72 & $\mathbf{( 0 . 5 5 , 0 . 9 2 )}$ \\
fund 2 vs 1 & 0.199 & 1.40 & 0.1609 & 1.22 & $(0.92,1.61)$ \\
sosc 2 vs 1 & 0.456 & 2.11 & $\mathbf{0 . 0 3 4 7}$ & 1.58 & $\mathbf{( 1 . 0 3 , ~ 2 . 4 1 )}$ \\
mwgc 2 vs 1 & -0.483 & -3.64 & $\mathbf{0 . 0 0 0 3}$ & 0.62 & $\mathbf{( 0 . 4 8 , 0 . 8 0 )}$ \\
\hline
\end{tabular}

Table 4: Adjusted Effects of PFI Factors, Ethnicity, Gender and Poverty (Measure of Socioeconomic Status) from M3 of Multiple Logistic Regression Analysis

\begin{tabular}{|c|c|c|c|c|c|}
\hline Effects & Est & tValue & Pvalue & OR & $95 \%$ CI (OR) \\
\hline ase 2 vs 1 & 0.351 & 2.61 & 0.0092 & 1.42 & $(1.09,1.85)$ \\
\hline vol 2 vs 1 & 0.366 & 2.33 & 0.0197 & 1.44 & $(1.06,1.96)$ \\
\hline asm 2 vs 1 & 0.289 & 1.87 & 0.0616 & 1.34 & $(0.99,1.81)$ \\
\hline aptm 2 vs 1 & -0.101 & -0.74 & 0.4582 & 0.90 & $(0.69,1.18)$ \\
\hline aptc 2 vs 1 & -0.221 & -1.72 & 0.0860 & 0.80 & $(0.62,1.03)$ \\
\hline fund 2 vs 1 & 0.187 & 1.32 & 0.1857 & 1.21 & $(0.91,1.59)$ \\
\hline $\operatorname{sosc} 2$ vs 1 & 0.426 & 2.00 & 0.0458 & 1.53 & $(1.01,2.32)$ \\
\hline $\operatorname{mwgc} 2$ vs 1 & -0.446 & -3.34 & 0.0008 & 0.64 & $(0.49,0.83)$ \\
\hline eth 2 vs 1 & 0.867 & 4.42 & $<.0001$ & 2.38 & $(1.62,3.49)$ \\
\hline eth 3 vs 1 & -0.234 & -1.56 & 0.1190 & 0.79 & $(0.59,1.06)$ \\
\hline eth 4 vs 1 & -0.447 & -0.77 & 0.4416 & 0.64 & $(0.20,2.00)$ \\
\hline eth 5 vs 1 & 0.170 & 0.79 & 0.4321 & 1.19 & $(0.78,1.81)$ \\
\hline gender 1 vs 2 & 0.887 & 6.37 & $<.0001$ & 2.43 & $(1.85,3.19)$ \\
\hline pov 1 vs 2 & 0.362 & 2.11 & 0.0345 & 1.44 & $(1.03,2.01)$ \\
\hline
\end{tabular}

As we look at the results of Table 4, for adjusted effects of underlying factors, it appears that the significance of some predictors in Table 2 and Table 3 are retained, and changed for others. Note that after adjusting for gender, ethnicity and poverty, the PFI factors such as attending school meeting (asm), attending parent teacher organizing committee (aptm), attending parent teacher conference (atpc) are not significant for high school students' suspension. Effects of other factors seem to have similar impact on suspension odds of high school students.

\section{Discussion and concluding remarks}

Disproportionate use of students' suspension is noted in the United States, with evidence of higher suspension for students of color (Arcia, E., 2007; Bland \& Mitchell, 2018; Gopalan \& Nelson, 2019; Morris \& Perry, 2017; 
Skiba et al., 2012; Sparks, 2018). Enormous adverse consequences of disproportionate suspensions have also been reported in literatures (Atkins et al., 2002; Balfanz et al., 2007; Fabelo et al., 2011; Gregory et al., 2010; Hoffmann, 2017; Kennedy-Lewis et al., 2016; Marchbanks et al., 2015; Noguera, 2003; Toldson, 2011; Weissman, 2015). For an example, suspensions funnel students of color out of classrooms and into jail cells (Weissman, 2015). Higher rates of suspension may have tremendous economic costs for the suspended student, the school, and the society (Marchbanks et al., 2015). Suspension practices are clear predictors of student dropout rates, graduation rates, and poor postsecondary outcomes (Balfanz et al., 2007).

Due to the noted evidence of disproportionality of students' suspensions and adverse consequences it might have in students' lives, economy and society, it has become necessary to look for factors contributing students' suspension and of its reduction. While a recent study (Bryant \& Wilson, 2020) tries to address the contribution of a few factors such as socioeconomic status, gender, and ethnicity in reference to high school students' suspension, it limits to a designated Charter high school in southern California. Therefore, the relevance of the findings may only be applicable to this school or to schools of similar sizes or demographic compositions (Bryant \& Wilson, 2020). Also, their study does not include parental involvement factors in response to the suspension, not been investigated before as well. We believe that parental involvement activities in education would have a positive impact in reducing students' suspension. To justify our belief, we investigate parental involvement activities for possible association with suspension and its role on students' suspension odds.

Our study noted that NH-Black students have higher suspension odds (compared to NH-White students), a conclusion similar to (Bland \& Mitchell, 2018; Loveless, 2017; Morris \& Perry, 2017; Skiba et al., 2012; Sparks, 2018). Conclusions of this study mostly agree with the conclusion of Bryant and Wilson (2020) with the exception that this study concludes that gender is a significant factor of suspension disproportionality. Our research findings supplement the findings of Bryant and Wilson (2020) in relation to the predictors of high school students' suspension odds due to the parent and family involvement factors. We provide evidence of disproportionate suspension odds due to parental involvement activity factors. Understanding significant parental involvement types and of their contributions towards the reduction of suspension episodes will be of great use in determining intervention or incentives for higher parental involvement in education, and thereby in the reduction of high school students' suspension. Given the insights and findings of this study, it will have a significant implication for practicing and policymaking and will be an instrumental to educators and policymakers as they seek to reduce students' suspension in the face of adverse students' outcomes.

Our study utilizes a broader-scale and nationally representative sample, and therefore, the conclusions being made are expected to be in relevance to the existing suspension disproportionality use in the United States. However, this study did not have any scope to investigate as to why non-engagement in meeting with guidance committee counselor (mwgc) or attending parent teacher conference (aptc) are found to be preventing factors regarding high school students' suspension. Further research could be targeted to investigate how students could be educated about the adverse effects of high school suspensions' by increasing significant parental involvement activities.

\section{References}

Arcia, E. (2007). A Comparison of Elementary/K-8 and Middle Schools' Suspension Rates. Urban Education, 42(5), 456-469. doi:10.1177/0042085907304879.

Atkins, M. S., McKay, M. M., Frazier, S. L., Jakobsons, L. J., Arvanitis, P., Cunningham, T., et al. (2002). Suspensions and detentions in an urban, low-income school: Punishment or reward. Journal of Abnormal Child Psychology, 30(4), 361-372.

Balfanz, R., Herzog, L., \& MacIver, D. (2007). Preventing student disengagement and keeping students on the graduation track in high-poverty middle-grades schools: Early identification and effective interventions. Educational Psychologist, 42(4), 223-235.

Bland, E., \& Mitchell, C. (2018). Black students bear uneven brunt of discipline, data show. Education Week. https://cut.ly/2KmsWcu

Boonk, L., Gijselaers, H. J., Ritzen, H., \& Brand-Gruwel, S. (2018). A review of the relationship between parental involvement indicators and academic achievement. Educational Research Review, 24, 10-30. 
Bryant, D., \& Wilson, A. (2020). Factors potentially influencing discipline referral and suspensions at an affiliated charter high school. Journal of Educational Research and Practice, 10, 119-128. https://doi.org/10.5590/JERAP.2020.10.1.08

Dotterer, A. M., \& Wehrspann, E. (2016). Parent involvement and academic outcomes among urban adolescents: Examining the role of school engagement. Educational Psychology, 36(4), 812-830.

Fabelo, T., Thompson, M. D., Plotkin, M., Carmichael, D., Marchbanks III, M. P., \& Booth, E. A. (2011). Breaking schools' rules: A statewide study of how school discipline relates to students' success and juvenile justice involvement. New York: The Council of State Governments Justice Center.

Gopalan, M., \& Nelson, A. A. (2019). Understanding the Racial Discipline Gap in Schools. AERA Open, 5(2), 1-26. doi:10.1177/2332858419844613.

Grace, M., \& Gerdes, A. C. (2019). Parent-teacher relationships and parental involvement in education in Latino families. Contemporary School Psychology, 23(4), 444-454.

Gregory, A., Skiba, R. J., \& Noguera, P. A. (2010). The achievement gap and the discipline gap: Two sides of the same coin? Educational Researcher, 39(1), 5968.

Hanson, R., Pugliese, C., \& Grady, S. (2020). Parent and Family Involvement in Education: 2019 First Look. The National Center for Education Statistics at Institute of Education Sciences, U.S. Department of Education. https://nces.ed.gov/pubs2020/2020076full.pdf

Hoffmann, F. (2017). From suspended to destitute: The disproportionate effect of out-of-school suspensions on low-income families. Indiana Journal of Law and Social Equality, 5(1), 169-195.

Kennedy-Lewis, B. L., Murphy, A. S., \& Grosland, T. J. (2016). Using narrative inquiry to understand persistently disciplined middle school students. International Journal of Qualitative Studies in Education, 29(1), 1-28. https://doi.org/10.1080/09518398.2014.974718

Lewis, C. W., Butler, B. R., Bonner, F. A., \& Joubert, M. (2010). African American male discipline patterns and school district responses resulting impact on academic achievement: Implications for urban educators and policy makers. Journal of African American Males in Education, 1(1), 7-25.

Liu, Y., Sulaimani, M. F., \& Henning, J. E. (2020). The significance of parental involvement in the development in infancy. Journal of Educational Research and Practice, 10, 161-166. https://doi.org/10.5590/JERAP.2020.10.1.11

Loveless, T. (2017). 2017 Brown Center Report on American education: Part III race and school suspensions. https://www.brookings.edu/research/2017-brown-center-report-part-iii-race-andschoolsuspensions/

Marchbanks III, M. P., Blake, J. J., Booth, E. A., Carmichael, D., Seibert, A. L., \& Fabelo, T. (2015). The economic effects of exclusionary discipline on grade retention and high school dropout. In D. J. Losen (Ed.), Closing the school discipline gap: Equitable remedies for excessive exclusion (pp. 59-74). New York: Teachers College Press.

Morris, E., \& Perry, B. (2017). Girls behaving badly? Race, gender, and subjective evaluation in the discipline of African American girls. Sociology of Education, 90(2), 127-148. https://doi.org/10.1177/0038040717694876.

National Center for Education Statistics (2019). Indicator 15: Retention, Suspension, and Expulsion. https://cut.ly/fSdNKxC

National Household Education Surveys (NHES) Program. (2019). National Center for Education Statistics, U.S. Department of Education. https://nces.ed.gov/nhes/ 
Parent and Family Involvement (PFI) in Education Survey (2019). National Household Education Surveys Parent and Family Involvement in Education Survey Public Use Datafile Codebook. https://nces.ed.gov/nhes/data/2019/pfi/cbook_pfi_pu.pdf

Noguera, P. A. (2003). Schools, prisons, and social implications of punishment: Rethinking disciplinary practices. Theory Into Practice, 42(4), 341-350.

Reinke, W. M., Smith, T. E., \& Herman, K. C. (2019). Family-school engagement across child and adolescent development. School Psychology, 34(4), 346.

SAS Institute. (2017). SAS/STAT® 14.3 User's Guide: Introduction to survey sampling and analysis procedures. SAS Institute Inc.

https://support.sas.com/documentation/onlinedoc/stat/143/introsamp.pdf

Skiba, R. J., Shure, L., \& Williams, N. T. (2012). Racial and ethnic disproportionality in suspension and expulsion. In A. L. Noltemeyer \& C. S. McLoughlin (Eds.), Disproportionality in education and special education (pp. 89-118).

Smith, E. J., \& Harper, S. R. (2015). Disproportionate impact of K-12 school suspension and expulsion on Black students in southern states. Philadelphia: University of Pennsylvania, Center for the Study of Race and Equity in Education.

Smith, T. E., \& Sheridan, S. M. (2019). The effects of teacher training on teachers' family-engagement practices, attitudes, and knowledge: A meta-analysis. Journal of Educational and Psychological Consultation, 29(2), 128-157.

Sparks, S. (2018). Suspension rates higher for students of color with disabilities, data show. Education Week. https://www.edweek.org/policy-politics/suspension-rates-higher-for-students-of-color-with-disabilities-datashow/2018/04.

Stetson, F. H., \& Collins, B. J. (2010). Rethinking suspensions. Principal Leadership, 11(2), 40-44.

Tan, C. Y., Lyu, M., \& Peng, B. (2019). Academic benefits from parental involvement are stratified by parental socioeconomic status: A meta-analysis. Parenting. Advance online publication. https://doi.org/10.1080/15295192.2019.1694836

Thompson, A. M., Herman, K. C., Stormont, M. A., Reinke, W. M., \& Webster-Stratton, C. (2017). Impact of Incredible Years on teacher perceptions of parental involvement: A latent transition analysis. Journal of School Psychology, 62, 51-65.

Toldson, I. A. (2011). Breaking barriers 2: Plotting the path away from juvenile detention and toward academic success for school-age African American males. Washington, DC: Congressional Black Caucus Foundation, Inc.

Weissman, M. (2015). Prelude to prison: Student perspectives on school suspension. Syracuse, NY: Syracuse University Press. 